УДК 37

DOI $10.21661 / \mathrm{r}-470571$

\title{
Л.К. Адамова
}

\section{О САМООБРАЗОВАНИИ РОДИТЕЛЕЙ}

Аннотация: в статье представлен понятийно-содержательный анализ самообразования, его функиий и видов в контексте исследования. Обозначаются результаты сочиологического опроса по вылялению потребностей у родителей в самообразовании. Для стимулирования самообразования родителей предлагаются решения и действия социально-организаџионного характера, направленные на создание благоприятных условий для их развития и поощрения.

Ключевые слова: образование взросльх, самообразование родителей, мотивы самообразования, формирование родительской культуры.

\section{L.K. Adamova}

\section{ON PEDAGOGICAL SELF-EDUCATION OF PARENTS}

Abstract: conceptual-content analysis of self-education, its functions and species in the context of research are presented in the article. The results of a sociological survey on revealing the parents' need for self-education are presented. To stimulate parents' self-education, solutions and actions of a socially-organizational nature are proposed, aimed at creating favorable conditions for its development and encouragement.

Keywords: adult education, self-education of parents, motives for self-education, parent's culture formation.

В свете современной гуманистической парадигмы самообразование представляется неотъемлемым элементом формирования личности, процессом, во многом определяющим уровень ее интеллектуального и профессионального развития. В основе самообразования лежит стремление человека устранить противоречия между предъявляемыми к нему обществом и самим собой требованиями 
и уровнем соответствия, и, таким образом, оно неотъемлемо от процесса социализации личности, является одним из его инструментов.

Последние исследования явления самообразования в практике педагогики позволяют развить ряд наиболее изученных аспектов: признаки самообразования, содержание самообразовательной деятельности, готовности к самообразованию, потребности в самообразовании, мотивы самообразования, виды самообразования, уровни самообразования, руководство самообразованием.

Проблемам стимулирования к самообразованию и педагогического содействия посвящены исследования Л.Н. Баренбаум, А.И. Гиро, А.Ю. Петрова и др.

Вопросами образования взрослых, в частности управления образованием взрослых, занимались Н.Б. Бакланова, С.И. Змеев, Е.М. Малитиков, В.И. Подобед и др.

Первые наиболее серьезные работы, посвященные систематизации сведений о самообразовании в педагогической теории, выполнены Н.А. Рубакиным.

Мы сравнили многие определения процесса самообразования и присущие ему признаки. В результате получили возможность сделать понятийно-содержательный анализ самообразования, его функций и видов в контексте нашего исследования.

Самообразование является одним из стержневых, активных элементов взаимосвязанных и взаимообусловленных процессов социальной адаптации и социализации личности.

Влияние образования на личность осуществляется через его социализирующие возможности. Это значит, что личность в процессе образования усваивает образцы поведения общества и социальных групп (общностей), куда она входит (либо соотносит свое поведение с их нормами и ценностями, имеется в виду референтные группы). В процессе образования происходит формирование жизненной позиции личности. Наконец в процессе образования осуществляется самореализация личности, ее самовыражение и самоутверждение. Основным субъектом 
самообразования является личность, которая удовлетворяет в нем целый ряд потребностей и социализируется. Именно эти два критерия - реализация (удовлетворение) потребностей и социализация - позволяют характеризовать в первую очередь функции самообразования.

С точки зрения первого критерия можно говорить об удовлетворении потребностей родителей в подготовке к выполнению роли воспитателей своих детей, общению, осуществлению семейно-бытовой деятельности и др.

С точки зрения второго критерия - социализация имеет смысл вести речь о таких функциях самообразования, как самоидентификация личности, ее самореализация, самоконтроль, самоопределение. Особое место здесь занимает такая функция самообразования, как приобщение с его помощью к определенной социальной группе, ее ценностям и нормам, осуществляемом в ходе самостоятельной работы человека над собой, усвоение этих норм и ценностей.

В рамках указанных двух функций внешние объективные условия и внутренние потребности личности реализуются через определенную совокупность интересов, поддающихся конкретному социологическому исследованию. В этом отношении мы разделяем точку зрения А.Ю. Петрова, выделившего пять групп интересов личности. Нам кажется, что эта группировка интересов может быть успешно применена к анализу самообразования. Трансформируем ее следующим образом.

Во-первых, это профессионально-трудовой интерес в сфере самообразования, выступающий как уверенность в том, что результаты данного вида деятельности будут внедрены в реальный процесс труда и профессионального совершенствования. Во-вторых, это материальный интерес к самообразованию, состоящий в понимании связи между ростом культурно-образовательного уровня и повышением вознаграждения за имеющиеся и примененные знания. В-третьих, это социально-статусный интерес к самообразованию, заключающийся в осознании зависимости социального признания, утверждения и продвижения от уровня 
культурно-образовательной компетентности и творческой инициативы. В-четвертых, это моральный интерес в сфере самообразования, являющийся побудительной силой уважения и самоуважения образованной личности в рамках общественной атмосферы значимости и востребованности знаний. В-пятых, это социально-педагогический интерес к самообразованию как фактору утверждения личности в качестве образца, примера образованной личности для собственной семьи (особенно детей) и окружающей социальной среды. В- шестых, это духовный интерес к самообразованию как средству самореализации личности, повышения ее образовательного, культурного, научного уровня.

Сферой самообразования в нашем случае выступает педагогическое самообразование родителей.

Среди содержательных критериев могут быть выделены целевые, показывающие, ради достижения каких целей осуществляется самообразование. В качестве целей педагогического самообразования родителей выступает рост культурного уровня, выход на новые рубежи осведомленности в области воспитания детей.

Еще одним содержательным критерием квалификации самообразования оказывается мотивация. Она связана с определенным образом с его целью. Дело в том, что для многих социальных групп и людей самообразование не является внутренней потребностью, жизненной необходимостью, а оказывается видом деятельности, которым следует заниматься для достижения определенных целей. Поэтому по существу цели диктуют мотивацию. Цели как бы превращаются в мотив этого вида деятельности.

Говоря о субъектных критериях выделения видов самообразования, необходимо отметить глубокие различия в его содержании, обусловленные тем, какие социальные группы и слои являются его «носителями». Родителями являются люди различных слоев, выполняющие разнообразные социальные роли. Для некоторых самообразование как вид деятельности как элемент их образа жизни не 
характерен. Их основные профессиональные роли (люди, занимающиеся тяжелым физическим трудом) не требуют самообразовательной деятельности. Есть такие группы родителей, для которых самообразование является важным средством их социальной (профессиональной) мобильности. В сельском социуме это - учителя, врачи, словом, представители интеллигенции.

Еще один, значимый для социологического исследования критерий квалификации - возрастной. В соответствии с ним можно говорить о различиях, существующих в самообразовании молодых, пожилых родителей и родителей среднего возраста.

Завершая понятийно-содержательный анализ самообразования, его функций и видов, мы считаем необходимым дать наше собственное определение этого понятия. В его основу целесообразно заложить несколько критериев: свободной деятельности, самореализации личности и многообразных потребностей, соединения самообразования с его субъектом, повышением общего уровня культуры и образования, социализации. Итак, самообразование родителей - это вид свободной деятельности родителей, характеризирующийся их свободным выбором и направленный на удовлетворение потребностей в сочуиализации, самореализации в роли воспитателей своих детей, повышении культурного и образовательного уровней.

Особенность этого определения состоит в том, что оно имеет операциональный характер и может быть трансформировано в программу (и ее часть - методический инструментарий) конкретно-педагогического исследования самообразования.

Условием и средством участия субъекта в самообразовании, по утверждению Баренбаум, является его готовность к самообразованию.

С целью выявления потребности в самообразовании, изучения условий для занятия самообразованием нами было опрошено 286 родителей учащихся сельских образовательных учреждений. Из них только 12, $6 \%$ читают специальную 
педагогическую литературу постоянно, 38,4\% - иногда, $39 \%$ родителей не читают. Смотрят телепередачи, слушают радио передачи постоянно - 27,3\%, иногда- 39,2\%, не смотрят и не слушают - 33,5\% родителей. Выписывают газеты или журналы, посвященные проблемам воспитания только 14, $7 \%$ опрошенных. Указали на отсутствие нужной литературы в библиотеке - 68,2\%.

Мотивом, побуждающим заниматься самообразованием, многие родители называют: желание понять своих детей, найти общий язык с детьми, решить проблемы, связанные с воспитанием детей.

Безусловно, наряду с другими социальными институтами, достаточно сильное влияние на формирование родительской культуры оказывают средства массовой информации: психолого-педагогическая литература, соответствующие передачи на радио, телевидении, журналы, газеты и т. д. Следует признать, что на сегодняшний день развитие средств массовой информации в контексте рассматриваемой проблемы имеет ряд положительных и отрицательных моментов. Прежде всего, новые социально-экономические условия привели к тому, что появилось значительное число печатной продукции, в том числе и той, что касается вопросов, связанных с воспитанием и развитием ребенка в семье. Усиление помощи родителям в воспитании детей видится через оказание финансовой поддержки издания массовым тиражом и распространения книг по воспитанию ребенка и уходу за ним, по проблемам семейных отношений; распространению специальной литературы для семьи среди молодых родителей, комплектования ею массовых библиотек.

Это книги, обучающие родителей, как нужно развивать эмоциональную, познавательную сферу ребенка, учить писать, считать, читать, ориентироваться в психологических и личностных особенностях того или иного возраста, находить верные пути решения проблемах воспитания, развития и обучения ребенка. Например, серии Библиотека для родителей, Библиотека для домашнего чтения и др. Появились многочисленные журналы для родителей: 
«Домашний очаг», «Parents» «Карапуз», «Мой кроха и я», «Наш малыш», «Очаг», «Мама», «Няня» «Отчий дом», «Материнство» и др., а также большое число печатных изданий для совместных занятий родителей с ребенком.

Однако, несмотря на многообразие предлагаемой печатной продукции, многие родители не всегда могут купить соответствующую литературу в связи с ее высокой стоимостью. Часто качественное содержание ее не отвечает запросам родителей: либо слишком наукообразно, не доступно и не понятно для людей, не имеющих достаточного образования, либо, рассматривает проблемы, дает рекомендации слишком далекие от реальной жизни. К тому же следует добавить, что подобную литературу читают в основном те родители, которые имеют высокий образовательный уровень, сильную мотивацию, желание изменить сложившуюся ситуацию в семье, найти ответы на возникающие вопросы, связанные с процессом воспитания взрослеющей личности.

То же самое касается радио- и телепередач. К сожалению, в настоящее время практически нет специализированных передач, целенаправленно ориентированных на формирование родительской культуры. В основном все передачи лишь косвенно затрагивают проблемы родительства: темы ранней беременности и формирования роли родителя, воспитания детей одним родителем, конфликтных ситуаций в семье, развития личности детей разных возрастов и др. Тем не менее, не давая готовых решений, они заставляют родителей задуматься над стилем собственного поведения, формами и способами взаимодействия с сыном или дочерью. Но вновь это относиться только к тем родителям, которые морально готовы к восприятию этой информации, к изменению собственной позиции, в вопросах воспитания, к оказанию определенной самопомощи в решении воспитательных проблем.

Вместе с тем, создавая соответствующие передачи, необходимо учитывать большое разнообразие родительской аудитории, этнопсихологические особенности, возрастной диапазон, религиозные взгляды, профессионально-образовательный уровень родителей. Кроме того, важно планомерно использовать средства 
массовой информации в деятельности других социальных институтов, исходя из того, что в целом они оказывают сильнейшее воздействие на формирование родительских установок, ценностного отношения, мотивированности к процессу воспитания ребенка в семье, а значит и на формирование педагогической культуры родителей.

Для стимулирования самообразования родителей нужна реализация системы решений и действий социально-организационного характера, направленных на создание благоприятных условий для его развития и поощрения. По нашему мнению, эти действия должны включать в себе следующие шаги:

1. Создание в общеобразовательных учреждениях специального центра самообразования.

2. Выпуск специального журнала для родителей.

3. Ориентация массовых средств информации на создание специальных рубрик, передач на тему воспитания детей.

4. Создание на базе библиотек или иных учреждений образования (культуры) специальных образовательных центров с оборудованной компьютерной базой.

5. Особое направление в работе учебных заведений - школ, лицеев, гимназий, связанное с обучением навыкам и умениям самообразовательной деятельности, самостоятельной деятельности.

6. Введение подразделений (отделов) организационно-методического и управленческого характера в образовательные структуры управления образования.

Таким образом, ясно одно: общеобразовательные учреждения не могут проходить мимо этой проблемы. В справедливости такого суждения убеждает анализ педагогической подготовленности родителей к воспитанию детей, осуществленный на материале исследования интереса, потребности родителей в педагогическом просвещении, мотивов и целей их самообразования. 


\section{Список литературы}

1. Адамова Л.К. Формирование педагогической культуры родителей школьников в сельском социуме: Автореф. дис. ... канд. пед. наук. - М., 2005.

2. Баренбаум Л.Н. Педагогическое содействие самообразованию студентов в высшем негосударственном образовательном учреждении.- Челябинск, 1997. -223 c.

3. Обучение в течение всей жизни. Политики и стратегии. (ЮНЕСКО, Доклад Института обучения в течение всей жизни). - 2014.

4. Обучение в течение всей жизни для взрослых. (Доклад Организации по экономическому сотрудничеству и развитию). - 2013.

5. Декларация Всемирного образовательного форума ЮНЕСКО (World Education Forum, 2015). - Инчхон (Республика Корея). -19-25.05.2015.

6. Петров А.Ю. Практико-ориентированный подход при дуальной подготовке квалифицированных кадров в профессиональной образовательной организации [Текст]: Учебно-методическое пособие: [16+] / А.Ю. Петров, Ю.Н. Петров, М.Н. Булаева. - Н. Новгород: НИРО, 2016. - 214 с.

7. Петров А.Ю. Развитие профессионализма педагога в профессиональной образовательной организации [Текст]: Учебно-методическое пособие: [16+] / А.Ю. Петров, Ю.Н. Петров, М.Н. Булаева. - Н. Новгород: НИРО, 2016. - 269 с.

\section{References}

1. Adamova L.K. Formation of pedagogical culture of parents of schoolchildren in rural society. Author's abstract. diss. ... cand. ped. sciences. - Moscow, 2005.

2. Barenbaum L.N. Pedagogical assistance to self-education of students in the higher non-state educational institution. - Chelyabinsk, 1997. - 223 p.

3. Lifelong learning. Policies and strategies. (UNESCO, Report of the Institute for Lifelong Learning). - 2014. 
4. Lifelong learning for adults. (Report of the Organization for Economic Cooperation and Development, 2013).

5. Declaration of the World Education Forum 2015, 19-25.05.2015, Incheon (Republic of Korea).

6. Petrov A.Yu. Practical-oriented approach to the dual training of qualified personnel in a professional educational organization [Text]: educational-methodical manual: [16 +] / A.Yu. Petrov, Yu.N. Petrov, M.N. Bulaeva. - Nizhny Novgorod: NIRO, 2016. $-214 \mathrm{p}$.

7. Petrov, A.Yu. Development of professionalism of the teacher in the professional educational organization [Text]: the educational-methodical grant: [16 +] / A.Yu. Petrov, Yu.N. Petrov, M.N. Bulaev. - Nizhny Novgorod: NIRO, 2016. - 269 p.

Адамова Любовь Константиновна - канд. пед. наук, доцент, заведующая кафедрой ФГБОУ ВО «Чурапчинский государственный институт физической культуры и спорта», Россия, Республика Саха (Якутия), с. Чурапча.

Adamova Lyubov Konstantinovna - candidate of pedagogical sciences, associate professor at the FGBOU VO «Churapchinsky State Institute of Physical Culture and Sport», Russia, the Republic of Sakha (Yakutia), Churapcha. 